\title{
REVIEW
}

\section{Protecting the ischaemic and reperfused myocardium in acute myocardial infarction: distant dream or near reality?}

\author{
D M Yellon, G F Baxter
}

Acute coronary occlusion is the leading cause of morbidity and mortality in the Western world, and according to the World Health Organisation will be the major cause of death in the world as a whole by the year $2020 .{ }^{1}$ Although the management of this epidemic will centre on the development of effective primary prevention programmes, the impact of these strategies may be limited, particularly in the developing countries. There is an urgent need for effective forms of secondary prevention and, in particular, treatments which will limit the extent of an evolving myocardial infarction during the acute phase of coronary occlusionthe death of myocardium represents a catastrophic event since dead myocytes are not replaced by division of surviving myocytes. Preserving the viability of ischaemic myocardium therefore presents a therapeutic target. Although appreciated for many years, this concept has so far failed to produce a clinically useful agent capable of protecting the ischaemic myocardium from infarction. The term "cardioprotection" has been used loosely during the last few decades to describe various therapeutic approaches, including antiarrhythmic, antianginal, antihypertensive, and antiplatelet treatments. In the present discussion, we apply the term "cardioprotection" very specifically to describe interventions that preserve or enhance the viability of myocardium during ischaemia and reperfusion and thus limit the extent of acute myocardial infarction. It is our contention that in the light of current understanding of the mechanisms of cell injury during both ischaemia and reperfusion, we are well placed to identify molecular targets which may provide the foundation on which rational therapeutic approaches can be based.

The Hatter Institute, Department of Academic \& Clinical Cardiology, University College London Hospitals \& Medical School, Grafton Way, London WC1E 6DB, UK

Correspondence to: Professor Yellon email:

hatter-institute@ucl.ac.uk

Accepted 6 January 2000 tration of injury modifying manoeuvres could occur either before the onset of ischaemia, or after the onset of ischaemia but before therapeutic reperfusion.

TREATMENT BEFORE ISCHAEMIA ONSET

Treatment of patients before the onset of coronary occlusion may be possible in some circumstances. For example patients with unstable angina may be at risk of myocardial infarction during the subsequent hours, weeks, and months. Such patients could be treated with a cardioprotective agent in addition to various antithrombotic treatments, etc. Identification of patients who do not have unstable angina but who have coronary disease and other risk factors predisposing to a future myocardial infarction is a more difficult issue. Ideally, if all patients at risk of myocardial infarction could be reliably identified they could be treated chronically with a cardioprotective agent, the aim of such treatment being to sustain the viability of the myocardium in the event of sudden coronary occlusion. Ultimately these patients would still require reperfusion treatment (thrombolysis, angioplasty or coronary artery bypass grafting (CABG)), but hopefully the progression of infarction would be delayed sufficiently by the cardioprotective pretreatment to reduce long term morbidity and mortality.

\section{TREATMENT AFTER ISCHAEMIA ONSET BUT} BEFORE REPERFUSION

Patients who present with severe chest pain already have coronary occlusion. The efficacy of protective manoeuvres which modify ischaemic injury would therefore be dependent on the degree of residual flow through the infarct related artery or the extent of coronary collateral opening. Under these circumstances, it is conceivable that a drug given as adjunctive treatment either before or in combination with thrombolytics might "buy time" before reperfusion patency, provided that there was some residual flow through the infarct related artery or a developed collateral circulation. Of equal interest, agents given after the onset of coronary occlusion might also be useful adjuncts to reperfusion treatment if they could modify reperfusion injury.

\section{Reperfusion injury}

Although reperfusion is the prerequisite for tissue salvage there is a price to pay in terms of 
four distinct reperfusion associated pathologies which pose a direct threat to the myocardium: reperfusion induced arrhythmias; myocardial stunning; reversible microvascular injury (endothelial stunning); and irreversible cell damage. ${ }^{4-7}$ This latter form of lethal reperfusion injury, distinct from, but additional to, lethal ischaemic injury, may be amenable to modification by cardioprotective agents. Recent advances in our understanding of cell death during both ischaemia and reperfusion implicate two forms of cell death in the pathology of myocardial infarction, namely necrosis and apoptosis (programmed cell death, cell suicide). We have hypothesised that the apoptotic component of tissue death may be particularly relevant at reperfusion and as such might be regarded as a target for intervention to limit lethal reperfusion injury, discussed in more detail below. Accordingly, a further indication for the use of certain cardioprotective agents would be the prevention of lethal reperfusion injury. The timing of cardioprotective treatments will thus be determined by the form of cell death which is targeted, in addition to the mechanism of action of the particular agent and the time at which the patient presents.

\section{Assessing pharmacological approaches to cardioprotection}

Over a number of years, many therapeutic manoeuvres have been proposed which might confer protection beyond that ascribable to reperfusion. None has been adopted in routine clinical practice as a cardioprotective intervention. Well known examples include magnesium treatment, which was the subject of two large and conflicting clinical trials (LIMIT-2 and ISIS $\left.-4^{8}{ }^{9}\right)$. Glucose-insulin-potassium treatment for acute myocardial infarction was first proposed more than 30 years ago, but has not been adopted routinely despite evidence of benefit in several trials and a subsequent meta-analysis. ${ }^{10}$ Antineutrophil interventions have been proposed to ameliorate some aspects of reperfusion injury such as the no-reflow phenomenon, but no positive clinical trial has yet been reported. Adenosine has been evaluated recently as an adjunct to reperfusion in the AMISTAD trial. This small trial provides evidence of anterior infarct size limitation but no evidence of morbidity/mortality benefit.

The design of clinical trials to assess the infarct limiting potential of agents is a complex (and costly) area of clinical science. There are important issues of patient recruitment, randomisation, selection of control treatments, choice of end point, and statistical power which are beyond the scope of this review. However, it is our belief that the sine qua non of clinical trial design in this area of investigation must be a complete appreciation of the scientific principles of infarct limitation and a thorough and rational interpretation of the preceding experimental literature relating to the agent in question. There are, regrettably, examples of large clinical trials being undertaken to assess interventions without full recognition of experimental studies. Interventions that do not limit infarction reliably in the laboratory are unlikely to limit infarction in the coronary care unit. The experimental literature of the 1970s and 1980 s is replete with conflicting and inconsistent studies of $\beta$ blockers, calcium channel blockers, anti-inflammatory drugs, inhibitors of neutrophil adhesion, and nitrates. Not surprisingly, none of these agents produce infarct limitation in clinical studies.

Agents which, in experimental models, consistently limit infarct size if given before ischaemia, but do not consistently limit infarct size when given only at reperfusion, are unlikely to be protective when used as clinical adjuncts to reperfusion. Adenosine is a good example of such an agent. When given before experimental coronary occlusion it limits infarct size notably and reliably (see the discussion on preconditioning below). However, when given during reperfusion in experimental animals its effects on infarction are not consistently reproducible. Thus the scientific rationale for its use as an adjunct to thrombolysis in the AMISTAD trial is weaker than one would like.

Thirdly, those experimental agents which modify lethal reperfusion injury when given during the first moments of reperfusion, but are not protective when their administration is delayed, must also be given during early reperfusion in clinical studies. In relation to this, we would say that there has been much discussion of the opposing findings of the LIMIT-2 and ISIS-4 magnesium trials. This issue has not been completely resolved. Experimental studies show that magnesium administration either before coronary occlusion or during the earliest moments of reperfusion can limit infarct size. If magnesium administration is delayed until after reperfusion, there is, as one might predict, no benefit. In the LIMIT-2 study magnesium was administered before thrombolysis and was protective. In the larger ISIS- 4 trial, magnesium was administered after thrombolysis and was not protective. Considered together these trials provide confirmation of the principles established in the laboratory, although it is surprising that a potentially useful treatment has been largely abandoned on the basis of the ISIS-4 findings.

We have illustrated how much of the disappointment and confusion with clinical infarct size limitation to date may be ascribed to failure to design clinical studies in the light of sound experimental studies. Ultimately, the selection of agents for clinical assessment should be driven by developments in basic science. As our understanding of the basic pathophysiological mechanisms of ischaemic injury, adaptation to ischaemia (preconditioning), and reperfusion injury have advanced during the last 5-8 years, it has become possible to identify ways in which the myocardium might be protected (fig 1).

\section{Advances in understanding of ischaemic injury: sodium-hydrogen exchange inhibitors}

An important advance during the last few years has been the understanding of the detrimental role played by the sodium-hydrogen exchange mechanism in the cardiac myocyte. ${ }^{12}{ }^{13}$ During 


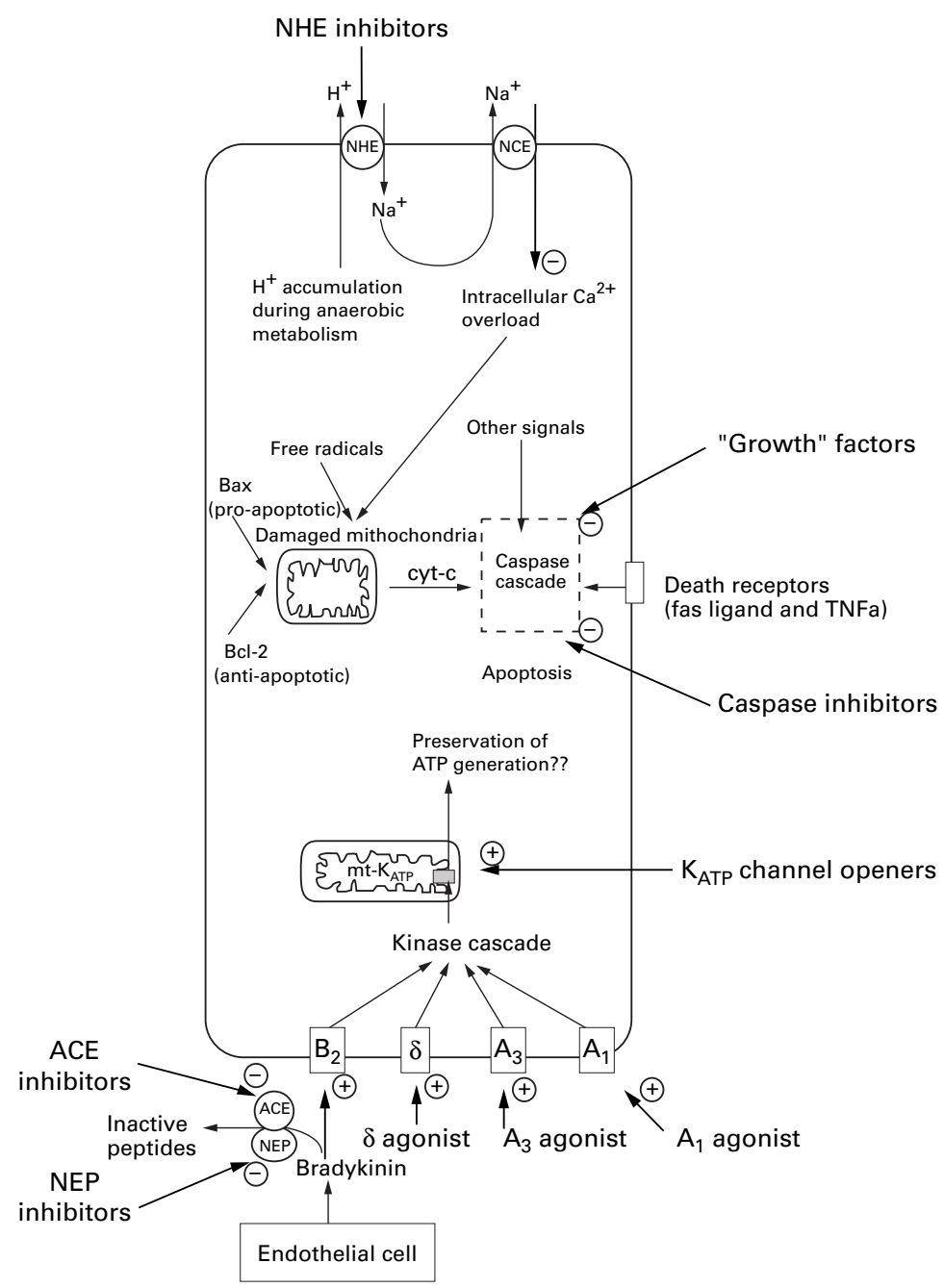

Figure 1 Modification of several molecular targets presents new therapeutic possibilities for limitation or delay of myocyte death during ischaemia and/or reperfusion. The figure summarises three promising approaches to infarct limitation during ischaemia and/or reperfusion. Top Intracellular accumulation of protons during ischaemia leads to the activation of the sarcolemmal sodium-hydrogen exchanger (NHE). Consequent intracellular sodium overload causes the activation of the sarcolemmal sodium-calcium exchanger (NCE) and predisposes to intracellular calcium overload. Inhibitors of NHE attenuate this mechanism of injury and can limit infarct size in experimental models. Bottom Preconditioning is an endogenous adaptive response in myocytes. Mediators released in ischaemic tissue include adenosine, noradrenaline, bradykinin, and opioid peptides. These mediators act via seven transmembrane $G$-protein coupled receptors on myocytes, (adenosine $A_{1}$ and $A_{3}$ receptors, $\delta$-opioid receptors, and bradykinin $B_{2}$ receptors) and initiate a complex kinase signalling cascade, which opens the $K_{\text {ATP }}$ channel in the mitochondrial inner membrane (mt-KATP). These channels are the likely end effector of preconditioning. Opening of the channel enhances myocyte viability during ischaemia through a mechanism that is likely to involve preservation of mitochondrial integrity and ATP generating capacity. There are several possibilities for exploitation of pharmacological preconditioning ("preconditioning mimetics"). Adenosine $A_{1}$ and $A_{3}$ receptor agonists and $\delta$-opioid receptor agonists activate the preconditioning signal cascade and limit infarct size in experimental models. Potentiation of endogenously generated bradykinin during ischaemia is possible with angiotensin converting enzyme (ACE) inhibitors and neutral endopeptidase (NEP) inhibitors. These agents prevent the breakdown of bradykinin and augment its protective effects on myocytes. Centre The predominant pathological feature of infarction is myocyte death by necrosis. However, apoptosis is now recognised as an additional mechanism of cell death which may be activated, particularly during reperfusion. Regulation of apoptotic pathways is extremely complex and incompletely understood, but inhibition of apoptosis may be a therapeutic route to salvage myocytes during ischaemia and/or reperfusion. Caspase inhibitors and counter regulatory growth factors limit infarct size when administered during the early reperfusion period.

ischaemia, myocyte intracellular $\mathrm{pH}$ decreases owing to the accumulation of protons. The sodium-hydrogen antiport mechanism in cardiac myocytes is activated to extrude these protons in exchange for sodium. In turn, intracellular sodium accumulation leads to reduced calcium efflux and/or increased calcium influx via the sodium-calcium exchanger mechanism, resulting in intracellular calcium overload and cell death.

One of the exciting developments over the last few years is the recognition that inhibiting the sodium-hydrogen exchange mechanism is a powerful means of delaying cell death during ischaemia. In experimental studies, these inhibitor compounds have proved to be consistently effective in limiting infarct size when administered before the onset of ischaemia. ${ }^{14-16}$ This therapeutic promise has been investigated in a large trial (11 500 patients) of cariporide, the GUARDIAN trial. ${ }^{17}$ The importance of this trial is that it is the first large clinical trial of a cardioprotective agent, whose primary mechanism of action is prevention of tissue necrosis. We view the trial as an example of how failure to recognise the message of the preclinical data can result in the design of an ambiguous clinical trial. Reduction in the primary end point (death plus myocardial infarction at 36 days) failed to reach significance.

GUARDIAN was a combined phase 2 and 3 trial with assessment of three different cariporide dosages. The combination of three patient subgroups in diverse clinical settings (unstable angina, high risk coronary angioplasty, and CABG) was ambitious. In the preclinical evaluation of cariporide there was clear evidence that pre-ischaemic administration was protective, but there was no unanimity that administration after the onset of ischaemia was cardioprotective. As such it is not surprising that the early subgroup analysis reveals CABG as being the only setting in which cariporide treatment was protective - that is, administration was before the commencement of a scheduled ischaemic event. Analysis is still under way but protection was observed only in the CABG group at high dose; because there were no serious adverse effects at any dose used, this suggests that there is the possibility of using higher doses to achieve protection in the correct setting.

\section{Advances in understanding of adaptation to ischaemia: preconditioning mimetic agents}

During the last decade there has been a major advance in our understanding of how myocardium can adapt to transient ischaemia. Brief periods of sublethal ischaemia precondition the heart to withstand a longer period of lethal ischaemia, slow the rate of tissue injury, and limit infarct size. ${ }^{18-21}$ Experimentally this protection has been shown to afford the myocardium a potent form of cardioprotection. ${ }^{21}$ There are two phases to this adaptive response: an early acute form of protection lasting approximately two hours; and a "second window" or delayed form of protection which develops over several hours, and lasts approximately three days. The molecular mechanisms underlying each form of preconditioning are incompletely understood but we now have the potential to use drugs which can induce preconditioning like responses.

During brief periods of ischaemia, a number of endogenous cardioprotective substances are released from ischaemic cardiac myocytes and 
endothelial cells which trigger the early and delayed preconditioning responses. In early preconditioning, these molecular triggers of adaptation include adenosine, bradykinin, and opioid peptides, acting on myocytes at the adenosine $A_{1} / A_{3}$ receptors, the bradykinin $B_{2}$ receptor, and the $\delta_{1}$-opioid receptor, respectively. Through a complex signal transduction mechanism, the phosphorylated target protein (or "end effector") appears to be the $\mathrm{K}_{\mathrm{ATP}}$ channel on the mitochondrial inner membrane, opening of which is thought to be cardioprotective. $^{22} 23$ Thus, both the endogenous triggers (adenosine, bradykinin, opioids) and the putative end effector of preconditioning, the ATP sensitive potassium channel $\left(\mathrm{K}_{\mathrm{ATP}}\right)$, present tangible therapeutic templates for anti-ischaemic drug development.

Adenosine was the first endogenous ligand to be identified as a trigger of the cardioprotective action of ischaemic preconditioning. Following an enormous amount of research it is clear that the infarct limiting effects of both endogenous adenosine and exogenously applied analogues work via the $\mathrm{A}_{1}$ and/or the $\mathrm{A}_{3}$ receptor subtypes in isolated cardiac myocytes, ${ }^{24}$ animal studies, ${ }^{25}{ }^{26}$ and human cardiac tissue ${ }^{27} 28$. Experimental studies also show that intermittent administration of low doses of $\mathrm{A}_{1}$ agonists confers cardioprotection over long periods without an adverse haemodynamic profile. ${ }^{29} 30$

Bradykinin has been identified as another important endogenous trigger of the preconditioning response. ${ }^{31}$ During periods of ischaemia considerable quantities of bradykinin are generated by the endothelium and exert important paracrine effects. However, the actions of endogenously generated bradykinin are brief because the peptide is rapidly metabolised. ${ }^{33}$ Exogenous administration of bradykinin induces cardioprotection but from a therapeutic perspective this has limitations since bradykinin has potent haemodynamic effects. There is an important class of agents already available and widely used, however, which potentiate the physiological actions of endogenous bradykinin generated during ischaemia by inhibiting its metabolism. These are the angiotensin converting enzyme (ACE) inhibitors, since ACE is a major route for bradykinin breakdown. It has been suggested for many years that ACE inhibitors are "cardioprotective" through ill defined mechanisms. The recognition that bradykinin is an endogenous cardioprotective substance provides a rationale for the use of ACE inhibitors in the setting of ongoing ischaemic heart disease where basal bradykinin concentrations may be augmented to a concentration sufficient to confer cardioprotection during an acute myocardial infarction. ${ }^{34}$ It may be relevant to add that neutral endopeptidase is another important metabolic pathway for bradykinin breakdown. Inhibitors of neutral endopeptidase, which are currently being developed for the treatment of hypertension and chronic heart failure, may offer a similar cardioprotective profile although there are no

\section{Trial acronyms}

AMISTAD: Adenosine as an Adjunct to Thrombolytic Therapy for Acute Myocardial Infarction

CESAR-2: Second Clinical European Studies in Angina and Revascularization

GUARDIAN: Guard During Ischemia Against Necrosis

ISIS-4: Fourth International Study of Infarct Survival

LIMIT-2: Second Leicester Intravenous Magnesium Intervention Trial

infarct size studies to support this concept at present.

In the ischaemic preconditioning response the role of endogenous opioid peptides as triggers of this phenomenon has also been identified, and it is now clear that these act through the $\delta$-receptor subtype activating the signalling cascade of preconditioning. ${ }^{35-37}$ Selective $\delta$-receptor agonists ${ }^{37} 38$ have been shown to induce cardioprotection in experimental models. Many of the opiates that are used clinically for their antinociceptive and analgesic properties are non-selective opioid receptor agonists. For example morphine will activate $\mu-, \kappa-$, and $\delta$-opioid receptors and has been shown to have some cardioprotective properties experimentally. ${ }^{39}{ }^{40}$ It is likely that a number of opiates used in cardiac surgery and coronary care including fentanyl, morphine, and diamorphine exert some $\delta$-opioid receptor activity. The potential cardioprotective properties of these agents, under these clinical conditions, is unproven at present. However, there is potential for developing selective $\delta$-opioid receptor agonists as cardioprotective agents, particularly for use in the settings of acute coronary syndromes and CABG, if treatment can be initiated before the index ischaemic event.

There is a growing consensus that the distal target or effector of protection is the $\mathrm{K}_{\mathrm{ATP}}$ channel. Initially research concentrated on the sarcolemmal $\mathrm{K}_{\mathrm{ATP}}$ channel as the downstream target of phosphorylation, but recent evidence has pointed to the mitochondrial inner membrane $\mathrm{K}_{\mathrm{ATP}}$ channel as the effector protein. ${ }^{22}{ }^{23}$ A number of experimental $\mathrm{K}_{\mathrm{ATP}}$ channel openers which have been shown to be cardioprotective are non-selective and open both channels. However, two agents are of particular interest as they open mitochondrial $\mathrm{K}_{\mathrm{ATP}}$ channel relatively selectively, namely diazoxide ${ }^{22}{ }^{23}$ and nicorandil. ${ }^{41}$ Selective pharmacological opening of mitochondrial $\mathrm{K}_{\text {ATP }}$ channels offers the potential for cardioprotection without haemodynamic perturbations (owing to sarcolemmal $\mathrm{K}_{\text {ATP }}$ channel opening in vascular smooth muscle) as has been shown in recent experimental studies. ${ }^{42}$ At present the only clinically available $K_{\text {ATP }}$ channel opener licensed for cardiovascular use is nicorandil. This agent also possesses nitrate activity which might account for its haemodynamic profile (coronary vasodilator and blood pressure lowering). 
However, the additional $\mathrm{K}_{\mathrm{ATP}}$ opening properties appear to account for the beneficial effects afforded to patients with unstable angina as seen in the recent CESAR 2 study. ${ }^{44}$ It therefore remains to be determined if the experimental promise of nicorandil will be realised by a direct cardioprotective action in patients. However, the results from CESAR 2, in which patients were already using nitrates, point to an action that goes beyond that of a nitrovasodilator.

It is important to appreciate that no matter how protective preconditioning or its pharmacological mimetics appear, the application of the protective treatment should occur before the episode of ischaemia. This point cannot be emphasised too strongly because there may be confusion when treatments linked to preconditioning are proposed as adjuncts to reperfusion (as with AMISTAD). There is little evidence that preconditioning triggers such as adenosine or modulators such as $\mathrm{K}_{\mathrm{ATP}}$ channel openers are protective when given after the onset of ischaemia, unless there is residual flow into the risk zone. There is no consensus in the experimental literature that they are able to limit infarct size when given at the time of reperfusion.

\section{Can we modify reperfusion injury?}

The approaches discussed so far have centred on treatment administered before the onset of myocardial ischaemia in an attempt to modify the ischaemic process and delay or slow the evolution of infarction. Unfortunately the majority of patients with evolving myocardial infarction will have had no heralding event and indeed may not have been identified at high risk. Treatments which need to be administered before the onset of ischaemia such as those described above may be of limited clinical efficacy since the majority of individuals present with an ongoing ischaemic episode. For these patients reperfusion represents the only means of limiting infarct size. However, as mentioned above, reperfusion comes at a price in terms of reperfusion injury, which may include further tissue death (lethal reperfusion injury). For the last two decades practical demonstration of lethal reperfusion injury has proved elusive. ${ }^{7}$ The most convincing means of demonstrating such lethal reperfusion injury is to administer agents that modify infarct size when given during the first moments of reperfusion. A number of agents have been examined in this setting and the outcome has been confusion and disappointment (see above).

Over the last two decades it was assumed that the mechanism of cell death during reperfusion was essentially a continuation or exacerbation of the necrotic process initiated during the preceding ischaemia. One of the most exciting developments in the last $4-5$ years is the recognition that apoptosis may be a pathological event relevant to ischaemia-reperfusion injury. It is likely that apoptosis occurs in addition to necrosis during ischaemia and reperfusion, both in experimental models and in clinical myocardial infarction. ${ }^{45}$ Because apoptosed cells are phagocytosed by adjacent cells, no inflammatory reaction occurs. Hence, detection of apoptosis by conventional histological approaches is very difficult. Using specialised techniques that detect DNA fragmentation, there is evidence that apoptosis occurs during ischaemia-reperfusion in addition to necrotic cell death. However, it is far from clear at what stage apoptosis occurs in relation to necrosis. It is also unclear whether it occurs predominantly during ischaemia or during reperfusion itself, although the balance of evidence suggests that apoptosis is accelerated by the process of reperfusion. ${ }^{46}$

Apoptosis may not have been previously recognised as a means of lethal injury during reperfusion. It is possible therefore that those agents examined over the years to limit lethal reperfusion injury may have been unsuccessful because they did not modify this potentially important component of myocardial death, whereas specific anti-apoptotic interventions may be better able to ameliorate lethal reperfusion injury. This approach is currently more speculative than those mentioned above, but recently various agents which block the

Table 1 Considerations for administration of infarct limiting treatments in acute myocardial infarction

\begin{tabular}{|c|c|c|c|}
\hline Clinical scenario & Treatment rationale & Choice of agent & Implications for trial \\
\hline $\begin{array}{l}\text { Patient at risk of acute } \\
\text { myocardial infarction, } \\
\text { eg, unstable angina. }\end{array}$ & $\begin{array}{l}\text { Pre-ischaemic pretreatment } \\
\text { to limit infarct size. }\end{array}$ & $\begin{array}{l}\text { "Preconditioning" mimetics, eg, } \\
\text { adenosine and selective receptor } \\
\text { agonists, } \mathrm{K}_{\mathrm{ATP}} \text { channel openers. Other } \\
\text { anti-ischaemic agents, eg, } \mathrm{Na} / \mathrm{H} \\
\text { exchange inhibitors. }\end{array}$ & $\begin{array}{l}\text { Several agents are protective if administered before coronary } \\
\text { occlusion. Clinically, timing of bolus treatment would be } \\
\text { difficult. Continuous pretreatment over an indefinite period } \\
\text { before infarction is the only feasible approach. For trial } \\
\text { purposes, only a limited number of unstable angina patients } \\
\text { would be available. }\end{array}$ \\
\hline $\begin{array}{l}\text { Patient presents with } \\
\text { evolving myocardial } \\
\text { infarction. Reperfusion } \\
\text { treatment is indicated. }\end{array}$ & $\begin{array}{l}\text { (a) Intra-ischaemic } \\
\text { treatment to limit ongoing } \\
\text { ischaemic injury is } \\
\text { dependent on access of drug } \\
\text { to the ischaemic risk zone } \\
\text { through either residual flow } \\
\text { in the infarct related artery, } \\
\text { a cyclical pattern of }\end{array}$ & $\begin{array}{l}\text { Anti-ischaemic agents must have } \\
\text { access to the risk zone during the early } \\
\text { ischaemic period. }\end{array}$ & $\begin{array}{l}\text { Drug access to the ischaemic risk zone would be } \\
\text { unpredictable. Some patients may benefit (eg, if there is some } \\
\text { residual flow) but because of inherent variability in effective } \\
\text { dosing of the risk zone, large numbers would be required to } \\
\text { show statistical benefit. Not an ideal scenario for a clinical } \\
\text { trial. Potential benefit of adenosine in AMISTAD may be via } \\
\text { an anti-ischaemic effect since experimental evidence for an } \\
\text { effect at reperfusion is conflicting. }\end{array}$ \\
\hline
\end{tabular}

A few clinically tested agents, eg, insulin and magnesium, may act predominantly in this mode. Experimental agents which attenuate reperfusion injury include various inhibitors of apoptosis.
Reperfusion injury may contribute $25-50 \%$ of final infarct size. Unless treatment is very potent, large numbers would be required to detect benefit. Reperfusion injury occurs early and timing of treatment is critical. Administration after reperfusion will reveal little or no effect, $\mathrm{cf}$ magnesium in LIMIT-2 and ISIS-4 trials. 
complex apoptotic pathways, given at reperfusion as a means of limiting lethal tissue injury, have undergone early preclinical evaluation. Naturally occurring modifiers of apoptosis include various "growth factors" which exert a counter regulatory action during development. We have hypothesised that growth factors are able to reduce lethal reperfusion injury by inhibiting apoptosis. In this respect we have observed that insulin, ${ }^{47}$ cardiotrophin-1, ${ }^{48}$ and transforming growth factor- $\beta_{1}\left(\text { TGF }-\beta_{1}\right)^{49}$ protect the myocardium from infarction if given at the onset of reperfusion. This protection is associated with a reduction in markers of apoptosis suggesting that this form of death contributes to lethal reperfusion injury. Interestingly such an antiapoptotic mechanism could, at least in part, explain the apparent benefit of insulin treatment given as glucose-insulin-potassium in patients with evolving myocardial infarction (see above). ${ }^{10}$ In addition to the potential for growth factors to modify apoptosis, other inhibitors of the caspase cascade, which results in apoptosis, may be amenable to further development. In particular the inhibition of caspase activity during ischaemia and/or reperfusion is currently receiving attention..$^{50-53}$

A summary of the treatment rationale and choice of agent for the differing clinical scenarios is presented in table 1 .

\section{Conclusion}

Recent advances in the fundamental biological sciences have brought a clearer understanding of the molecular pathology of infarction. It is now appreciated that there are at least two forms of cell death relevant to myocardial infarction, namely necrosis and apoptosis. There is awareness of the ways in which myocardium can adapt to ischaemia and thereby protect itself against otherwise lethal ischaemic insult, and we have an appreciation of the molecular triggers, cell signalling pathways, and target proteins associated with protection. In view of these developments, there is cause for optimism about new drug classes with cellular actions directly relevant to tissue protection. More than at any other time in the past, it is conceivable that specific pharmacological treatments can be developed to protect the ischaemic and reperfused myocardium through direct targeting of cytoprotective pathways. Ultimately, convincing demonstrations of cardioprotection in patients with acute myocardial infarction can come only from rigorously designed trials that follow on from reliable laboratory studies, using the most appropriate drugs, administration protocols, and clinical scenarios.

1 Lopez AD, Murray CCJL. The global burden of disease, 1990-2020. Nature Med 1998;4:1241-3.

2 Simmons WW, Armstrong PW. Thrombolytic therapy in acute myocardial infarction. Curr Opin Cardiol 1993;8:60412 .

3 Anderson HV, Willerson JT. Current concepts: thrombolysis in acute myocardial infarction. $N$ Eng $\mathcal{F}$ Med 1993;329: 703-9.

4 Yellon DM, Downey JM. Current research views on myocardial reperfusion and reperfusion injury. Cardiomyocardial reperfusion
science 1990;1:89-98.

5 Braunwald E, Kloner RA. Myocardial reperfusion: double-edged sword? F Clin Invest 1985;76:1713-19.
6 Opie LH. Reperfusion injury and its pharmacologic modification. Circulation 1989;80:1049-62.

7 Jennings RB, Reimer KA. Lethal reperfusion injury: fact or fancy? In: Parratt JR, ed. Myocardial response to acute injury. London: MacMillan, 1992:17-34.

8 Woods KL, Fletcher S, Roffe C, et al. Intravenous magnesium sulphate in suspected acute myocardial infarction: results of the second Leicester intravenous magnesium intervention trial (LIMIT-2). Lancet 1992;339: 1553-8.

9 ISIS-4 (Fourth International Study of Infarct Survival) Collaborative Group. ISIS-4: a randomised factorial trial assessing early oral captopril, oral mononitrate, and intravenous magnesium sulphate in 58050 patients with suspected acute myocardial infarction. Lancet 1995; 345:669-85.

10 Fath-Ordoubadi F, Beatt KJ. Glucose-insulin-potassium therapy for treatment of acute myocardial infarction: an overview of randomized placebo-controlled trials. Circulation 1997;96:1152-6.

11 Mahaffey KW, Puma JA, Barbagelata NA, et al. Adenosine as an adjunct to thrombolytic therapy: results of a multicenter, randomized, placebo-controlled trial: the acute myocardial infarction study of adenosine (AMISTAD) trial. F Am Coll Cardiol 1999;34:1711-20.

12 Karmazyn M. The sodium-hydrogen exchange system in the heart: its role in ishemic and reperfusion injury and therapeutic implications. Can $\mathcal{F}$ Cardiol 1996;12:1074-82.

13 Frolich O, Karmazyn M. The Na-H exchanger revisited: an update on $\mathrm{Na}-\mathrm{H}$ exchange regulation and the role of the exchanger in hypertension and cardiac function in health and disease. Cardiovasc Res 1997;36:138-48.

14 Bugge E, Munch-Ellingsen J, Ytrehus K. Reduced infarct size in the rabbit heart in vivo by ethylisopropyl-amiloride. A role for $\mathrm{Na}^{+} / \mathrm{H}^{+}$exchange. Basic Res Cardiol 1996;91: A role 9 .

15 Gumina RJ, Mizumura $\mathrm{T}$, Beier $\mathrm{N}$, et al. A new sodium/hydrogen exchange inhibitor, EMD 85131, limits infarct size in dogs when administered before or after coronary artery occlusion. F Pharmacol Exp Ther 1998;286:

16 Linz W, Albus U, Crause P, et al. Dose-dependent reduction of myocardial infarct mass in rabbits by the NHE-1 inhibitor cariporide (HOE 642). Clin Exp Hypertens 1998;20: $733-49$

17 Erhardt LRW. GUARD during ischemia against necrosis GUARDIAN) trial in acute coronary syndromes. $A m \mathcal{F}$ Cardiol 1999;83:23G-25G.

18 Parratt JR. Protection of the heart by ischaemic preconditioning: mechanisms and possibilities for pharmaprecondi exploitation. Trends Pharmacol Sci 1994;15:19-25.

19 Yellon DM, Baxter GF, Marber MS. Angina re-assessed: pain or protector? Lancet 1996;347:1059-62.

20 Przyklenk K, Kloner RA. Ischemic preconditioning: exploring the paradox. Prog Cardiovasc Dis 1998;40:517-47.

21 Yellon DM, Baxter GF, Garcia-Dorado D, et al. Ischaemic preconditioning: present position and future directions. Cardiovasc Res 1998;37:21-33.

22 Garlid KD, Paucek P, Yarov-Yarovoy V, et al. Cardioprotective effect of diazoxide and its interaction with mitochondrial ATP-sensitive $\mathrm{K}+$ channels. Possible mechanism of cardioprotection. Circ Res 1997;81:1072-82.

23 Liu Y, Sato T, O'Rourke B, et al. Mitochondrial ATPdependent potassium channels: novel effectors of cardioprotection? Circulation 1998;97:2463-9.

24 Wang J, Drake L, Sajjadi F, et al. Dual activation of adenosine $\mathrm{A} 1$ and $\mathrm{A} 3$ receptors mediates preconditioning of isolated cardiac myocytes. Eur $\mathcal{F}$ Pharmacol 1997;320:241-8.

25 Liu GS, Thornton J, Van Winkle DM, et al. Protection against infarction afforded by preconditioning is mediated against infarction afforded by preconditioning is mediated 1991;84:350-6.

26 Tracey WR, Magee W, Masamune H, et al. Selective adenosine A3 receptor stimulation reduces ischemic myocardial injury in the rabbit heart. Cardiovasc Res 1997;33:410-15.

27 Walker DM, Walker JM, Pugsley WB, et al. Preconditioning in isolated superfused human muscle. $\mathcal{F} \mathrm{Mol}$ Cell Cardiol 1995;27:1349-57.

28 Carr CS, Hill RJ, Masamune H, et al. Evidence for a role for both the adenosine $\mathrm{A} 1$ and $\mathrm{A} 3$ receptors in protection of isolated human atrial muscle against simulated ischaemia. Cardiovasc Res 1997;36:52-9.

29 Dana A, Baxter GF, Walker JM, et al. Prolonging the delayed phase of myocardial protection: repetitive adenosine A1 receptor activation maintains rabbit myocardium in a preconditioned state. F Am Coll Cardiol 1998;31:1142-9.

30 Travers A, Middlemiss D, Louttit JB. Cardioprotection after Travers A, Middlemiss D, Louttit JB. Cardioprotection after
repeated dosing with GR79236, an adenosine A1 agonist [abstract]. Br F Pharmacol 1998;124(suppl):102P.

31 Goto M, Liu Y, Yang XM, et al. Role of bradykinin in protection of ischemic preconditioning in rabbit hearts. Circ Res 1995;77:611-21.

32 Wall TM, Sheehy R, Hartman JC. Role of bradykinin in myocardial preconditioning. I Pharmacol Exp Ther 1994; 270:681-9.

33 Parratt JR, Vegh A, Papp JG. Bradykinin as an endogenous myocardial protective substance with particular reference to ischemic preconditioning-a brief review of the evidence. Can f Physiol Pharmacol 1995;73:837-42.

34 Heusch G, Rose J, Ehring T. Cardioprotection by ACE inhibitors in myocardial ischaemia/reperfusion. The importance of bradykinin. Drugs 1997;54(suppl 5):31-41. 35 Schultz JJ, Hsu AK, Gross GJ. Ischemic preconditioning and morphine-induced cardioprotection involve the 
d-opioid receptor in the intact rat heart. $\mathcal{F} \mathrm{Mol}$ Cell Cardiol 1997:29:2187-95.

36 Tsuchida A, Miura T, Tanno M, et al. Time window for the contribution of the delta-opioid receptor to cardioprotection by ischemic preconditioning in the rat heart Cardiovasc Drugs Ther 1998;12:365-73.

37 Aitchison KA, Baxter GF, Yellon DM, et al. Involvement of delta opioid receptor subtype in ischaemic preconditioning against infarction in isolated rat heart [abstract]. $\mathrm{Br} \mathcal{F}$ Pharmacol 1998;124(suppl):22P.

38 Schultz JJ, Hsu AK, Nagase H, et al. TAN-67, a delta 1 -opioid receptor agonist, reduces infarct size via activation of $\mathrm{Gi} / \mathrm{o}$ proteins and KATP channels. Am $\mathcal{f}$ Physio 1998;274:H909-14.

39 Schultz JEJ, Hsu AK, Gross GJ. Morphine mimics the cardioprotective effect of ischemic preconditioning via a glibenclamide-sensitive mechanism in the rat heart. Circ Res 1997;78:1100-4

40 McCormack KJ, Chapleo CB. Opioid receptors and myocardial protection. Clin Drug Invest 1998;15:445-54.

41 Sato T, Sasaki N, O'Rourke B, et al. Nicorandil activates miotchondrial ATP-dependent potassium channels in rabbit ventricular cells [abstract]. Circulation 1998;98(suppl): I-343.

42 Imagawa J, Baxter GF, Yellon DM. Myocardial protection afforded by nicorandil and ischaemic preconditioning in a rabbit infarct model in vivo. $\mathcal{F}$ Cardiovasc Pharmacol 1998; 31:74-9.

43 Mizumura T, Nithipatikom K, Gross GJ. Infarct-size reducing effect of nicorandil is mediated by the KATP channe but not by its nitrate-like properties in dogs. Cardiovasc Res 1996;32:274-85

44 Patel DJ, Purcell HJ, Fox KM. Cardioprotection by opening of the KATP channel in unstable angina. Is this a clinical manifestation of myocardial preconditioning? Results of a
randomized study with nicorandil. Eur Heart $f$ 1999;20:517 .

45 Bartling B, Holtz J, Darmer D. Contribution of myocyte apoptosis to myocardial infarction? Basic Res Cardiol 1998; 93:71-84.

46 Fliss H. Accelerated apoptosis in reperfused myocardium: friend or foe? Basic Res Cardiol 1998;93:90-3.

47 Jonassen AK, Brar BK, Mjos OD, et al. Insulin modifies myocyte apoptosis and reduces myocardial infarct size when administered at reperfusion: a novel mechanism of protection [abstract]. Br F Pharmacol 1999;126(suppl): 201P.

48 Cai Q, Brar B, Stephanou A, et al. Cardiotrophin-1 reduces infarct size in an isolated rat heart model via a MAP kinase depednent pathway [abstract]. F Physiol 1999;518P:16P.

49 Mocanu MM, Baxter GF, Yellon DM. Transforming growth factor- $\beta 1$ limits infarct size when administered prior to reperfusion in an isolated rat heart model [abstract]. $\mathrm{Br} \mathcal{F}$ Pharmacol 1999;126(suppl):198P.

50 Yaoita H, Ogawa K, Maehara K, et al. Attenuation of ischemia/reperfusion injury in rats by a caspase inhibitor. Circulation 1998;97:276-81.

51 Ruetten H, Gehring D, Busch A. Caspase inhibitors improve post-ischaemic functional recovery in rat isolated working hearts. Br 7 Pharmacol 1999;126(suppl):200P.

52 Endres M, Namura S, Shimizu-Sasamata M, et al. Attenuation of delayed neuronal death after mild focal ischemia in mice by inhibition of the caspase family. 7 Cereb Blood Flow Metab 1998;18:238-47.

53 Mocanu MM, Baxter GF, Yellon DM. Caspase inhibition at reperfusion protects the isolated rat heart. Circulation 1999;100(suppl):I-10.

\section{IMAGES IN CARDIOLOGY}

\section{Candle flame appearance in dissection of aorta}



A 40 year old man underwent transoesophageal echocardiography for suspected dissection of aorta. Dissection extended from T7 vertebral level to L2 vertebral level. At the exit point of the dissection, there was a tiny opening through which a jet of blood flowed from the false lumen to the true lumen. The appearance produced a candle shaped image on colour Doppler imaging (Ao, aorta).

K M KRISHNAMOORTHY
P K DASH
V R IYER

